\title{
Blood Conservation in Neurosurgery: Erythropoietin and Autologous Donation
}

\author{
Alexander McGirr, Katerina Pavenski, Bhanu Sharma, Michael D. Cusimano
}

\begin{abstract}
Background: Neurosurgery may involve significant blood loss and frequently requires allogeneic red blood cell (RBC) transfusion. Preoperative recombinant erythropoietin (EPO) may be used to improve erythroid status and recovery, and used either alone or in combination with preoperative autologous donation (PAD) it may reduce exposure to allogeneic RBC. We wished to study the use of EPO with and without PAD and the risk of RBC transfusion in neurosurgery. Methods: Using a retrospective case-control design, 57 patients who received EPO preoperatively were matched 2:1 for age, sex, year of surgery, and International Classification of Diseases code most responsible for surgery (three were excluded because of stringent matching criteria, leaving 54 cases and 108 comparison subjects). Thirty-two cases participated in PAD. Medical and anesthetic records as well as laboratory investigations were reviewed and extracted. Results: Allogeneic RBC exposure was identical for EPO cases and comparison subjects (18.5\%). Concomitant PAD and EPO did not reduce allogeneic RBC exposure (21.9\%), and resulted in a greater number of RBC units transfused. Last recorded hemoglobin levels suggested that autologous RBCs were not more liberally used. Patients who engaged in PAD and EPO suffered from iatrogenic anemia. A significant proportion (58.6\%) of the autologous RBCs was ultimately not used and discarded. Conclusion: Further research is needed to determine the efficacy of EPO in neurological surgery. PAD does not appear to reduce the risk of allogeneic RBC transfusion, despite concomitant EPO. Indeed, PAD resulted in iatrogenic anemia and increased transfusion requirements. The cost-effectiveness of blood conservation efforts in neurosurgery deserves additional research.
\end{abstract}

RÉSUMÉ: Conservation de sang en neurochirurgie. Contexte: La neurochirurgie peut donner lieu à une perte de sang importante qui nécessite fréquemment le recours à la transfusion de globules rouges (GR) allogènes. L'étythropoïétine recombinante (EPO) en période préopératoire peut être utilisée pour améliorer le statut érythroïde et favoriser la guérison. Elle peut être utilisée seule ou combinée à un don autologue préopératoire (DAP) et ainsi diminuer l'exposition aux GR allogènes. Le but de l'étude était d'examiner l'utilisation d'EPO avec ou sans DAP et le risque de transfusion de GR en neurochirurgie. Méthode: Il s'agit d'une étude rétrospective cas-témoin portant sur 57 patients qui ont reçu de l'EPO avant la chirurgie. Ils ont été appariés 2:1 pour l'âge, le sexe, l'année de la chirurgie et le motif de la chirurgie, identifié selon le code de la Classification internationale des maladies (3 patients ont été exclus à cause des critères rigoureux d'appariement). L'étude porte donc sur 54 patients et 108 témoins. Trente-deux patients ont eu recours à un DAP. Les dossiers médicaux et d'anesthésie ainsi que les examens de laboratoire ont été revus. Résultats: L'exposition à des GR allogènes a été identique chez les patients ayant reçu de l'EPO et chez les sujets témoins (18,5\%). L'administration de DAP et d'EPO n'a pas diminué l'exposition aux GR allogènes $(21,9 \%)$ et a donné lieu à la transfusion d'un plus grand nombre d'unités de GR. La dernière valeur d'hémoglobine au dossier suggérait que les GR autologues n'étaient pas utilisés de façon plus libérale. Les patients qui avaient participé à un DAP et qui ont reçu de l'EPO ont souffert d'anémie iatrogène. Une proportion significative (58.6\%) des GR autologues n'a pas été utilisée et ils ont été jetés. Conclusion: Des recherches plus poussées seront nécessaires pour déterminer l'efficacité de l'EPO en neurochirurgie. Le DAP ne semble pas diminuer le risque de transfusion de GR allogènes malgré l'administration concomitante d'EPO. En effet, le DAP a mené à une anémie iatrogène et a augmenté le recours à la transfusion. Le rapport coût-efficacité des efforts de conservation du sang en neurochirurgie mérite qu'on l'étudie davantage.

Keywords: Erythropoietin, neurosurgery, preoperative autologous donation, red blood cells, transfusion

doi:10.1017/cjn.2014.14

Can J Neurol Sci. 2014; 41: 583-589

The advent of modern transfusion medicine improved surgical survival and morbidity; however, the legacy of transfusion-related blood-borne infections lingers in public perception. Although the implementation of strategies to avoid transfusion were once an infrequent occurrence limited to populations such as Jehovah's Witnesses or individuals with rare antibodies, individuals preparing for surgery are increasingly likely to ask to avoid transfusion. ${ }^{1}$

The safety of allogeneic blood products is constantly improving. Yet, despite improved donor screening and testing, the risk of viral infection remains. ${ }^{1}$ The risks also include noninfectious complications such as hemolysis from clerical errors, lung injuries, and volume overload. $^{2}$ Although transfusions requirements may reflect more challenging surgical cases or an increased burden of disease, they have been shown to be associated with worse outcomes

From the Injury Prevention Research (AM, MDC), St-Michael's Hospital, University of Toronto, Toronto, ON, Canada; Department of Psychiatry (AM, BS), University of British Columbia, Vancouver, Canada; Department of Laboratory Medicine (KP), St-Michael's Hospital and Department of Laboratory Medicine and Pathobiology, University of Toronto, Toronto, ON, Canada; Division of Neurosurgery (MDC), St-Michael's Hospital, University of Toronto, Toronto, ON, Canada.

Received January 14, 2014. Final Revisions Submitted March 13, 2014. Correspondence to: Alexander McGirr, Injury Prevention Research, St. Michael's Hospital, 30 Bond Street, Toronto, ON, Canada, M5B 1W8. Email: alexander. mcgirr@alum.utoronto.ca, injuryprevention@smh.ca. 
in perioperative patients including postoperative infections, most typically pneumonia and bacteremia, ${ }^{3}$ and increased length of stay. ${ }^{1}$ In addition to rigorous transfusion protocols, surgical planning and optimized intraoperative hemostasis, there are several approaches to limit blood loss and avoid allogeneic red blood cell (RBC) transfusion, including diagnosis and management of preoperative anemia, use of hemostatic medications, normovolemic hemodilution, controlled hypotensive anesthesia, salvaging and reinfusing RBCs lost intraoperatively, and preoperative $\mathrm{RBC}$ donation through preoperative autologous donation (PAD). ${ }^{1}$

An additional method to manage anemia and hasten erythroid recovery is to use erythroid-stimulating agents such as erythropoietin (EPO). The advent of recombinant erythropoietic-stimulating agents provided a mechanism for improving erythroid status in many settings, including renal disease, myelodysplastic syndromes, and anemia of chronic disease. ${ }^{4}$ When used to prevent perioperative allogeneic blood products, meta-analyses of randomized controlled trials indicate that recombinant erythropoiesis-stimulating agents reduce allogeneic RBC transfusion in cardiovascular ${ }^{5,6}$ and orthopedic surgeries. ${ }^{6}$ Furthermore, when used in conjunction with PAD, recombinant erythropoiesis-stimulating agents reduce the risk of allogeneic transfusion in orthopedic and cardiovascular surgeries. ${ }^{5-7}$

Early experience in neurological surgery with recombinant EPO to avoid RBC transfusion involved successful use in Jehovah's Witnesses in both spine ${ }^{8}$ and intracranial cases. ${ }^{9,10}$ There was a prospective open-label randomized control trial of erythropoiesisstimulating agents in spinal surgery ${ }^{11}$; however, to our knowledge, there are limited data on its use in nonspinal neurological surgeries.

Although meta-analyses have shown that PAD reduces exposure to allogeneic RBC, it also results in an increased exposure to transfusion when both autologous and allogeneic RBCs are considered, ${ }^{12}$ most likely because of iatrogenic anemia. It is unknown whether this is a consideration when planning blood conservation efforts in neurosurgery.

The Ontario Transfusion Coordinators (ONTraC) Provincial Blood Conservation program is involved in patient blood management efforts in 27 sites across Ontario, Canada. This program seeks to minimize the use of allogeneic blood products through various techniques, including management of anemia with EPO and PAD. The program specifically targets certain surgical procedures such as coronary artery bypass grafting and arthroplasty, but will accept referrals for patients undergoing other surgeries.

The aim of this study was to characterize RBC transfusion requirements among neurosurgical patients who received erythropoiesis-stimulating agents with PAD and without versus comparison subjects who were matched for age, sex, and preoperative diagnosis.

\section{Methods}

This study was approved by the St-Michael's Hospital Research Ethics board. This was a retrospective case control study. No mention of patient status as a Jehovah's Witness was identified in any of the cases studied.

\section{Subjects}

\section{Cases}

The ONTraC program was launched in 2002 with the aim of minimizing unnecessary use of allogeneic blood products. It coordinates patient blood management programs in institutions of all sizes in Ontario. ONTraC's targeted procedures include total knee and hip arthroplasty/replacement, coronary artery bypass graft surgery, and radical prostatectomy. ONTraC nurses also consider referrals for patients undergoing other surgical procedures.

Between 2002 and 2009, 420 patients received recombinant EPO preoperatively through the ONTraC program at St-Michael's Hospital. Fifty-seven of these were neurosurgical patients and were retained in the current study. International Classification of Diseases (ICD)-10 codes for the preoperative diagnosis were extracted for all cases to permit comparison subject matching (Table 1). Ultimately, three cases were not included in the final analyses (encephalocele $n=1$, cerebral cyst $n=2$ ) because comparison subjects could not be identified that respected our matching protocol.

\section{Blood Conservation}

Cases received iron supplementation and an average of $2.44 \pm 1.0040,000 \mathrm{IU}$ subcutaneous doses of EPO preoperatively.

\section{Table 1: Preoperative diagnoses}

\begin{tabular}{|c|c|c|}
\hline Diagnosis & $\begin{array}{l}\text { ICD-10 } \\
\text { code }\end{array}$ & $\begin{array}{c}\mathbf{N} \\
\text { index }\end{array}$ \\
\hline Cysticercosis of central nervous system & B69.0 & 1 \\
\hline Malignant neoplasm of spinal meninges & $\begin{array}{l}\text { C70.1 } \\
\text { D32.9 }\end{array}$ & 1 \\
\hline Malignant neoplasm of brain & C71.- & 1 \\
\hline Malignant neoplasm of craniofacial bones & $\mathrm{C} 41.00$ & 6 \\
\hline Malignant neurilemmoma & $9560 / 3$ & 1 \\
\hline Neurilemmoma NOS & $9560 / 0$ & 1 \\
\hline Benign neoplasm of meninges & D32.9 & 14 \\
\hline Benign neoplasm of meninges with trigeminal neuralgia & $\begin{array}{l}\text { D32.9 } \\
\text { G50.0 }\end{array}$ & 2 \\
\hline Benign neoplasm of cranial nerves & D33.3 & 4 \\
\hline Trigeminal neuralgia & G50.0 & 2 \\
\hline Spondylolisthesis of lumbar region & M43.16 & 1 \\
\hline Spinal stenosis of lumbar region & M48.06 & 4 \\
\hline $\begin{array}{l}\text { Intervertebral disc disorders: Nerve root and plexus } \\
\text { compressions }\end{array}$ & G55.1 & 3 \\
\hline $\begin{array}{l}\text { Osseous and subluxation stenosis of intervertebral } \\
\text { foramina }\end{array}$ & M99.6 & 1 \\
\hline Myelopathy in disease classified elsewhere & G99.2 & 1 \\
\hline Cerebral aneurysm, nonruptured & I67.1 & 1 \\
\hline Benign neoplasm of pituitary gland & D35.2 & 6 \\
\hline Benign neoplasm of pituitary gland with acromegaly & $\begin{array}{l}\text { D35.2 } \\
\text { E22.0 }\end{array}$ & 2 \\
\hline $\begin{array}{l}\text { Benign neoplasm of pituitary gland with Cushing's } \\
\text { syndrome }\end{array}$ & $\begin{array}{l}\text { D35.2 } \\
\text { E24.0 }\end{array}$ & 1 \\
\hline Brain damage due to birth injury & $\mathrm{P} 11.2$ & 1 \\
\hline \multicolumn{3}{|l|}{ Excluded } \\
\hline Frontal encephalocele with meningitis & Q01.0 G01 & 1 \\
\hline Cerebral cyst & G93.0 & 2 \\
\hline
\end{tabular}

$\mathrm{ICD}=$ International Classification of Diseases 
Recombinant EPO for the purposes of blood conservation is not covered under Canadian socialized health care; therefore, the costs of the treatment were covered by insurance providers $(n=27,47.3 \%)$, the patients themselves $(n=13,22.8 \%)$, compassionate access program $(n=8,14.0 \%)$, or by the Ontario Drug Benefit program $(n=9,15.7 \%)$. Concomitant to receiving EPO, $32(59.2 \%)$ cases also elected to participate in a preoperative autologous donation program. The patients donated an average of $1.78 \pm 1.13$ whole blood units (range 1-3 units); one patient donated 3 units twice because of rescheduling.

\section{Comparison Subjects}

Controls were identified through the St-Michael's Hospital registry. Cases were matched 2:1 to comparison subjects identified among elective neurosurgical patients. To be included, comparison subjects could not be emergency cases. Cases were matched for ICD-10 preoperative diagnosis, sex, age ( \pm 3 years), and year of surgery ( \pm 3 years). ONTraC files were consulted to ensure that no comparison subject participated in blood conservation programs, including preoperative autologous RBC donation or intraoperative reinfusion. Thus, 108 matched comparison neurosurgical patients were identified and included in this study.

\section{RBC Transfusion}

Participation in the ONTraC program does not result in a mandated transfusion guideline. All decisions to proceed to RBC transfusions were managed by the patients' most responsible physician as clinically indicated. This is unlikely to have resulted in any systematic biases with respect to transfusions.

\section{Data Extraction}

Patients' charts were reviewed for information pertaining to preoperative diagnosis, age, and sex. Preoperative neurosurgical, medical, and anesthesia consultations were reviewed for comorbidities-specifically hematological, renal, hepatic, pulmonary, and cardiovascular - and medications, including antiplatelet and anticoagulant use. Laboratory values, namely hemoglobins and platelet counts, were extracted when available.

The primary outcome for this study was allogeneic RBC transfusion. Secondary outcomes were RBC units transfused and perioperative hemoglobins, particularly day-of-surgery hemoglobins. Additional analyses are presented for relevant laboratory values.

\section{Statistical Analyses}

Statistical analyses were performed with SPSS v19 (SPSS Inc., Chicago, IL). For categorical variables, we used chi-square tests (with odds ratio and $95 \%$ confidence interval). For continuous variables, we used Student-t test or analysis of variance. Significance was set at $\alpha \leq 0.05$.

\section{RESULTS}

Demographic and clinical characteristics of EPO cases, subdivided according to PAD, and comparison subjects are presented in Table 2. Cases and controls were of identical sex distribution (24.1\% male, $75.9 \%$ female) and comparable age $(50.31 \pm 13.78$ vs $50.83 \pm 14.15)$. Some clinical differences emerged: cases who received EPO without PAD were more likely to have comorbid diabetes mellitus, and preoperative hemoglobin was lower for cases that received EPO both with and without autologous predonation. Of note, the difference between patients who did not receive any blood conservation measures versus those who received EPO alone the difference in preoperative hemoglobins was about $10 \mathrm{~g} / \mathrm{L}$. Cases were otherwise comparable with respect to medical comorbidities, anticoagulant, and antiplatelet use.

Surgical matching was also achieved, with spinal surgeries involving comparable number of levels $(2.58 \pm 0.79$ vs $2.20 \pm 0.76$ levels, $p \geq 0.19)$. Similarly, mean tumor volume did not differ between groups $\left(29.16 \pm 34.71\right.$ vs $28.85 \pm 43.17 \mathrm{~cm}^{3}$, $\mathrm{p} \geq 0.97$ ).

\section{Allogeneic RBC Transfusion}

Cases and controls did not differ with respect to exposure to allogeneic RBCs (Figure 1a), and an identical proportion (18.5\%) were exposed to allogeneic RBCs. Similarly, they did not differ with respect to the number of allogeneic units transfused (Figure 2a; $F(2,161)=0.34, p \geq 0.70)$. When distinguishing cases that received EPO and predonated blood, no difference in exposure to allogeneic RBCs was noted (Figure $1 \mathrm{~b} ; \chi^{2}=1.61$, $\mathrm{df}=2$, $\mathrm{p} \geq 0.44$ ). Cases that required an allogeneic transfusion did not differ from patients who did not with respect to the number of EPO doses received $(2.50 \pm 1.26$ vs $2.43 \pm 0.94, \mathrm{p} \geq 0.84)$.

\section{Recombinant EPO and PAD}

Because 32 (59.2\%) of cases concomitantly participated in preoperative EPO and PAD, we also considered autologous RBC transfusion. When considering all units of RBCs transfused, cases who received EPO and predonated autologous RBCs were more likely to have been transfused (Figure 1c; 46.9\%; $\chi 2=13.39$, $\mathrm{df}=2, \mathrm{p} \leq 0.001)$ and have received a greater number of $\mathrm{RBC}$ units (Figure $2 b ; F(2,161)=3.77, p \leq 0.05)$.

We characterized cases' hemoglobin levels before EPO and on the day of surgery (Figure 3). Analyses revealed a significant interaction between predonation status $\times$ time $(F(1,46)=6.49$, $\mathrm{p} \leq 0.05)$ after controlling for the main effects of predonation status $(\mathrm{F}(1,46)=0.87, \mathrm{p} \geq 0.35)$ and time $(\mathrm{F}(1,46)=3.58$, $\mathrm{p} \geq 0.06)$.

Cases that concomitantly participated in preoperative autologous donation did not receive a different number of EPO doses than patients who did not $(2.56 \pm 0.98$ vs $2.27 \pm 1.03 \mathrm{t}(52)=1.04$, $\mathrm{p}=0.30)$. Of these cases, $15(46.9 \%)$ were transfused autologous RBCs. Ultimately, $58.6 \%$ of the autologous units donated (34 units) were not transfused and were discarded.

\section{Transfusion Threshold}

Because participation in ONTRaC does not involve mandated transfusion guidelines and PAD RBCs may be viewed as more benign, we examined the final hemoglobins for our transfused cases and comparison subjects as proxies for transfusion threshold. There were no differences between patients who had received transfusions belonging to the EPO group $(99.66 \pm 13.86 \mathrm{~g} / \mathrm{L})$, the EPO with PAD group $(98.73 \pm 10.57 \mathrm{~g} / \mathrm{L})$, or the comparison group $(103.33 \pm 13.36 \mathrm{~g} / \mathrm{L} ; \mathrm{F}(2,35)=.59, \mathrm{p} \geq 0.55)$. 


\section{Table 2: Demographic and clinical features}

\begin{tabular}{|c|c|c|c|c|}
\hline & $\begin{array}{l}\text { Erythropoietin and } \mathrm{RBC} \text { predonation cases } \\
\qquad(\mathrm{N}=32)\end{array}$ & $\begin{array}{l}\text { Erythropoietin cases } \\
\qquad(\mathbf{N}=22)\end{array}$ & $\begin{array}{l}\text { Comparison subjects } \\
\qquad(\mathrm{N}=\mathbf{1 0 8})\end{array}$ & $\chi^{2}$ or $F$ ( $p$ value) \\
\hline & $\mathbf{N}(\%)$ or $\mathrm{M} \pm \mathrm{SD}$ & $\mathbf{N}(\%)$ or $M \pm S D$ & $\mathbf{N}(\%)$ or $\mathbf{M} \pm \mathrm{SD}$ & \\
\hline Age & $48.88 \pm 13.33$ & $52.41 \pm 14.46$ & $50.83 \pm 1.36$ & $\mathrm{~F}(2,161)=.43(0.646)$ \\
\hline Sex (male) & $8(25.0 \%)$ & $5(22.7 \%)$ & $26(24.1 \%)$ & $.03(0.982)$ \\
\hline Hypertension & $6(18.8 \%)$ & $9(40.9 \%)$ & $27(25.0 \%)$ & $3.25(0.197)$ \\
\hline Diabetes mellitus & $1(3.1 \%)$ & $3(13.6 \%)$ & $3(2.8 \%)$ & $7.15(0.028)$ \\
\hline Aortic stenosis & $2(6.3 \%)$ & $0(0.0 \%)$ & $1(0.9 \%)$ & $4.33(0.115)$ \\
\hline Chronic obstructive pulmonary disease & $0(0.0 \%)$ & $2(9.1 \%)$ & $4(3.7 \%)$ & $3.02(0.221)$ \\
\hline Asthma & $1(3.1 \%)$ & $0(0.0 \%)$ & $1(0.9 \%)$ & $1.29(0.523)$ \\
\hline $\begin{array}{l}\text { Rheumatological/inflammatory bowel } \\
\text { disease }\end{array}$ & $2(6.3 \%)$ & $0(0.0 \%)$ & $3(2.8 \%)$ & $1.80(0.405)$ \\
\hline Hypothyroidism & $1(3.1 \%)$ & $3(13.6 \%)$ & $14(13.0 \%)$ & $2.58(0.275)$ \\
\hline Hepatitis C & $1(3.1 \%)$ & $0(0.0 \%)$ & $1(0.9 \%)$ & $1.29(0.523)$ \\
\hline Comorbid carcinoma & $0(0.0 \%)$ & $1(4.5 \%)$ & $4(2.7 \%)$ & $1.31(0.519)$ \\
\hline Liver failure & $1(3.1 \%)$ & $0(0.0 \%)$ & $1(0.9 \%)$ & $1.29(0.523)$ \\
\hline \multicolumn{5}{|l|}{ Hematological } \\
\hline B-thalassemia & $0(0.0 \%)$ & $1(4.5 \%)$ & $0(0.0 \%)$ & \\
\hline Monoclonal gammopathy & $0(0.0 \%)$ & $1(4.5 \%)$ & $0(0.0 \%)$ & \\
\hline Myelodysplastic & $0(0.0 \%)$ & $0(0.0 \%)$ & $1(0.9 \%)$ & \\
\hline \multicolumn{5}{|l|}{ Medications } \\
\hline Coumadin & $0(0.0 \%)$ & $1(4.5 \%)$ & $1(0.9 \%)$ & $2.46(0.292)$ \\
\hline Acetylsalicylic acid & $3(9.4 \%)$ & $4(18.2 \%)$ & $7(6.5 \%)$ & $3.19(0.202)$ \\
\hline Laboratory values & $\mathrm{M} \pm \mathrm{SD}$ & $\mathrm{M} \pm \mathrm{SD}$ & $\mathrm{M} \pm \mathrm{SD}$ & F; p value \\
\hline $\mathrm{Hb}$ - preoperative & $120.19 \pm 17.80$ & $122.37 \pm 17.56$ & $133.70 \pm 16.00$ & $\begin{array}{c}F(2,154)=10.15 \\
\leq 0.001\end{array}$ \\
\hline $\mathrm{Hb}$ - postoperative day 0 & $108.07 \pm 10.95$ & $113.79 \pm 15.32$ & $113.77 \pm 18.28$ & $\mathrm{~F}(2,119)=1.29 ; 0.278$ \\
\hline $\mathrm{Hb}$ - Postoperative day 1 & $105.37 \pm 15.94$ & $106.60 \pm 14.05$ & $111.10 \pm 16.05$ & $\mathrm{~F}(2,122)=1.57 ; 0.211$ \\
\hline $\mathrm{Hb}$ - Postoperative day 2 & $109.81 \pm 19.60$ & $108.00 \pm 15.79$ & $110.63 \pm 17.96$ & $\mathrm{~F}(2,85)=.10 ; 0.903$ \\
\hline $\mathrm{Hb}$ - Postoperative day 3 & $103.48 \pm 13.96$ & $103.13 \pm 15.22$ & $108.34 \pm 19.30$ & $\mathrm{~F}(2,81)=.85 ; 0.429$ \\
\hline Plts - Preoperative & $282.00 \pm 114.59$ & $307.53 \pm 77.98$ & $272.06 \pm 82.68$ & $\mathrm{~F}(2,148)=1.27 ; 0.283$ \\
\hline Plts - Postoperative day 0 & $233.89 \pm 100.03$ & $285.58 \pm 67.44$ & $234.13 \pm 86.42$ & $\mathrm{~F}(2,116)=2.77 ; 0.067$ \\
\hline Plts - Postoperative day 1 & $222.54 \pm 83.13$ & $268.57 \pm 74.78$ & $233.05 \pm 75.20$ & $\mathrm{~F}(2,115)=1.67 ; 0.192$ \\
\hline Plts - Postoperative day 2 & $220.36 \pm 83.15$ & $261.36 \pm 83.59$ & $230.55 \pm 92.56$ & $\mathrm{~F}(2,82)=.70 ; 0.497$ \\
\hline Plts - Postoperative day 3 & $206.50 \pm 58.64$ & $242.93 \pm 73.90$ & $241.17 \pm 94.13$ & $\mathrm{~F}(2,78)=1.45 ; 0.239$ \\
\hline
\end{tabular}

$\mathrm{Hb}=$ hemoglobin $\mathrm{M}=$ mean Plts = platelets $\mathrm{RBC}=$ red blood cell $\mathrm{SD}=$ standard deviation .

\section{DISCUSSION}

Using a case-control design, our analyses suggest that PAD does not reduce the risk of allogeneic RBC transfusion in neurological surgery, despite having been used in conjunction with EPO. Indeed, PAD was associated with an increase in transfusion requirements when both allogeneic and autologous RBCs are considered. Our data suggest that PAD resulted in patients going into surgery with lower hemoglobin levels, and therefore that autologous donation rendered patients anemic despite the concomitant use of EPO. Indeed, without reducing the risk of exposure to allogeneic RBC, concomitant EPO and PAD resulted in a greater number of total RBC units transfused. These findings are in keeping with systematic reviews and meta-analyses demonstrating that PAD is associated with lower preoperative hemoglobin levels ${ }^{13}$ and increases the risk of any transfusion. ${ }^{12,13}$

Although our analyses cast doubt on the utility of PAD, our data cannot determine whether EPO used in isolation is effective at reducing allogeneic $\mathrm{RBC}$ exposure in neurosurgery. We recommend careful selection of patients for patient blood management; these should include patients with preoperative anemia and cases associated with a significant risk of blood loss and thus allogeneic transfusion, patients objecting to transfusions, and perhaps those for whom it may be difficult to find compatible RBCs.

Further, there are counterbalanced data suggesting that recombinant EPO is not without risk. The oncology literature suggests 

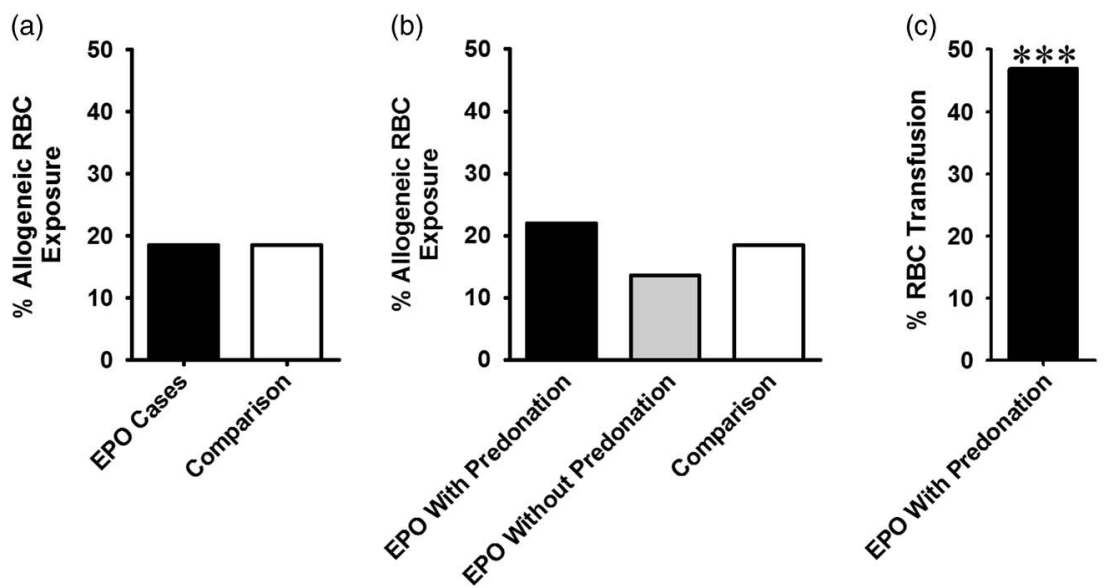

Figure 1: Proportion of patients exposed to allogeneic RBC units subdivided according to (a) whether or not they received EPO and (b) whether they received EPO in conjunction with PAD or not. In (c), the proportion of patients who engaged in PAD and received EPO who required RBC transfusion (allogeneic and autologous). ***p $\leq 0.001$.
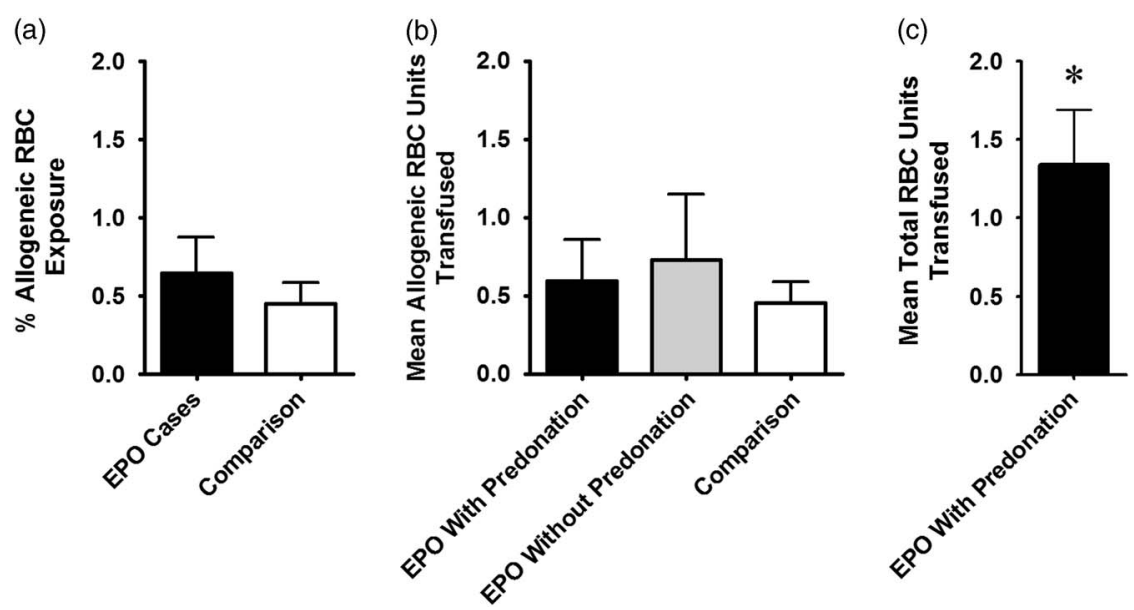

Figure 2: Mean allogeneic $R B C$ requirements for (a) patients who received EPO and comparison subjects, (b) subdivided EPO patients into those who also engaged in PAD or did not, and $(c)$ the total RBC transfusion requirements (allogeneic and autologous) for patients with $P A D$ and EPO. * $p \leq 0.05$.

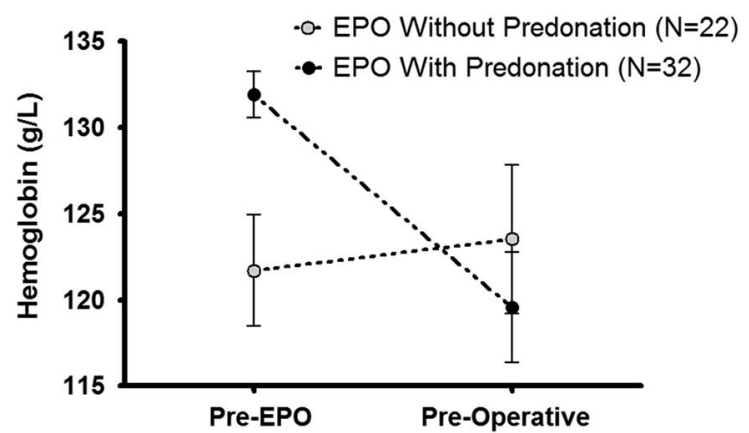

Figure 3: Hemoglobin prerecombinant erythropoietin and preoperatively. $*_{p} \leq 0.05$.

that chronic use of erythropoiesis-stimulating agents is associated with poorer long-term survival ${ }^{4,14}$; however, this remains controversial. $^{15,16}$ Adverse events associated with chronic use of EPO include hypertension, thromboembolism, and iron deficiency. ${ }^{17}$
When given acutely, as in blood conservation programs, the risk of each of these drops significantly, yet the risk of thromboembolism remains elevated (3-9\%). ${ }^{6,17,18}$ As such, the risks may not be counterbalanced in light of limited benefit of EPO, and additional research is required to justify the use of such agents because they may expose neurosurgical patients to unnecessary harm.

Although the individual and societal value of avoiding allogeneic blood products should not be minimized, the utility of PAD and EPO in neurosurgery to prevent allogeneic RBC transfusion should be carefully evaluated. Although efficacy has been well demonstrated in surgeries with a high risk for RBC transfusionsuch as cardiac surgery where transfusion rates are approximately $40 \%{ }^{19}$ but approach $90 \%$ in some samples ${ }^{20}$-rates of transfusion in neurological surgery are far lower, between $2 \%$ and $25 \% .^{21,22}$ Intrinsically, the possible absolute risk reduction will be constrained by a floor effect in surgeries with a lower risk of RBC transfusion; therefore, the ability to demonstrate the efficacy of blood conservation strategies in neurological surgery will be limited. Our results suggest that PAD and EPO may not be equally 
effective across surgical interventions. Indeed, EPO has not been demonstrated effective in colorectal cancer surgery, ${ }^{23}$ and the same may be true in neurological surgery.

Considering the low likelihood of requiring a transfusion in neurosurgery, PAD may not be warranted. PAD may be associated with increased risk of adverse events during donation as compared with allogeneic donation. ${ }^{24}$ PAD is associated with increased risk of requiring any transfusion ${ }^{12,13}$ and does not eliminate the risk of transfusion complications such as volume overload or acute hemolysis resulting from a clerical error. The increased transfusion requirements of neurosurgical patients undergoing PAD was demonstrated even in conjunction with EPO, which highlights the need for further research into the benefit of PAD in neurosurgery.

We could not identify the reasons for which patients elected to participate in blood conservation strategies; no cases selfidentified as Jehovah's Witness. Analyses examining pre-EPO hemoglobins suggest that preoperative anemia may have been the primary reason among those who did not participate in PAD, whereas personal preference may explain those who did. Indeed, 17 patients received recombinant EPO that was specially funded by the Ontario Drug Benefit program or through compassionate use to treat low hemoglobin. These same 17 patients did not, then, donate autologous RBC; because of their low hemoglobin levels, they were not deemed to be candidates for PAD. With our data, it is not possible to conclude that preoperative erythropoietin did not optimize erythroid status and hasten postoperative erythroid recovery and thereby prevent blood transfusions in these patients.

\section{Economic Cost-Benefit}

The economic cost-benefit analysis of preoperative EPO and autologous donation in neurosurgery deserves discussion. Canadian Blood Services reports the cost of an RBC unit to be $\$ 367 \mathrm{CAD},{ }^{25}$ including collection and testing. However, the activity-based cost of transfusing an RBC unit is closer to $\$ 760$ $\mathrm{CAD}^{26}$ Autologous blood must undergo the same infectious disease and pretransfusion testing as allogeneic blood. However, about two-thirds of autologous units are routinely discarded (Pavenski, personal communication, 2013) suggesting that the true cost of producing an autologous unit is in fact much higher compared with an allogeneic one. At the same time, the Ontario Drug Benefit formulary lists recombinant EPO alfa 40,000 IU at $\$ 450$ CAD per dose.

In light of these costs, neurosurgical cases in the current study received recombinant erythropoietin at a mean cost of $\$ 1098$, before administration costs. Cases participating in autologous predonation did so at a mean cost of $\$ 1352.80$ CAD. Most important, whether EPO was used in isolation (representing $40.8 \%$ of the sample) or in conjunction with PAD (59.2\% of the sample; mean per capita cost \$2504.80), it did not reduce the absolute risk of receiving allogeneic $\mathrm{RBC}$, nor did it reduce the number of allogeneic RBC units transfused compared with comparison subjects matched for age, sex, and preoperative diagnosis; with comparable tumor burden or number of spinal levels; and medical comorbidities.

Under Canadian transfusion standards, autologous units cannot cross over into the general blood inventory because autologous blood collection does not involve the rigorous screening of donors for potential exposures required for allogeneic blood.
If unused, autologous units can only be discarded. Almost $60 \%$ of the autologous RBC units in this cohort were ultimately disposed of, at a cost exceeding $\$ 25,000$.

\section{Limitations}

This study is subject to limitations inherent in retrospective case-control designs; nevertheless, we used strict matching criteria and achieved a comparison population with similar demographic and clinical characteristics. Unfortunately, because of our strict matching procedure, three cases were not retained in the final analyses because comparison patients could not be identified. Moreover, we could not, by design, control for the surgeons and anesthetists who were involved in the surgeries. Similarly, we did not capture operative duration and this should be addressed in future studies. Although we matched according to ICD-10 codes and achieved similar tumour burden, we cannot definitely rule out more vascular lesions among our cases, and angiographic characterization should be considered in future studies.

A major limitation of our study is that cases and controls were not matched for hemoglobins, and this methodological shortcoming may have influenced our results. Further, because $\mathrm{RBC}$ transfusions were initiated according to the clinical judgment of the patient's most responsible physician, additional research should include a standardized transfusion protocol that controls for this potential confound. Although the use of final hemoglobin as a proxy for transfusion thresholds suggests the absence of bias and that autologous RBCs were not viewed as a more benign intervention, we cannot definitively exclude this possibility. Another limitation is that our data did not systematically capture adverse events that may have been related to PAD or EPO.

\section{Conclusion}

In this cohort of patients undergoing neurological surgery, preoperative EPO did not result in a lower rate of allogeneic $\mathrm{RBC}$ transfusion. When used in conjunction with preoperative autologous donation, it similarly did not reduce the risk of allogeneic RBC transfusion or the number of transfused allogeneic units. Our data do not address whether EPO used in isolation reduces the risk of exposure to allogeneic RBCs; analyses revealed that our patients who received EPO but did not engage in PAD nevertheless went into surgery with a $10 \mathrm{~g} / \mathrm{L}$ hemoglobin deficit compared with controls without a corresponding increase in transfusion requirements. The utility of PAD and EPO in neurological surgery is deserving of additional research using randomized prospective designs, as the non-neglible cost and side-effect profile of these strategies require sound evidence to justify their implementation in neurosurgery.

\section{ACKNOWLEDGMENTS}

We thank Alanna Howell, Anna Nassis, and Katherine Luke, Ontario Transfusion Coordinators nurses at St-Michael's Hospital, for their blood conservation efforts and support of this research.

\section{REFERENCES}

1. Spahn DR, Goodnough LT. Alternatives to blood transfusion. Lancet. 2013;381(9880):1855-65. 
2. Goodnough LT. Risks of blood transfusion. Crit Care Med. 2003;31 (12 Suppl):S678-86

3. Horvath KA, Acker MA, Chang $\mathrm{H}$, et al. Blood transfusion and infection after cardiac surgery. Ann Thorac Surg. 2013;95(6): 2194-2201.

4. Bohlius J, Schmidlin K, Brillant C, et al. Recombinant human erythropoiesis-stimulating agents and mortality in patients with cancer: a meta-analysis of randomised trials. Lancet. 2009;373 (9674):1532-42.

5. Alghamdi AA, Albanna MJ, Guru V, Brister SJ. Does the use of erythropoietin reduce the risk of exposure to allogeneic blood transfusion in cardiac surgery? A systematic review and metaanalysis. J Card Surg. 2006;21(3):320-6.

6. Laupacis A, Fergusson D. Erythropoietin to minimize perioperative blood transfusion: a systematic review of randomized trials. The International Study of Peri-operative Transfusion (ISPOT) Investigators. Transfus Med. 1998;8(4):309-17.

7. Shapiro GS, Boachie-Adjei O, Dhawlikar SH, Maier LS. The use of Epoetin alfa in complex spine deformity surgery. Spine (Phila Pa 1976). 2002;27(18):2067-71.

8. Joseph SA Jr., Berekashvili K, Mariller MM, et al. Blood conservation techniques in spinal deformity surgery: a retrospective review of patients refusing blood transfusion. Spine (Phila Pa 1976). 2008;33(21):2310-15.

9. Schiff SJ, Weinstein SL. Use of recombinant human erythropoietin to avoid blood transfusion in a Jehovah's Witness requiring hemispherectomy. Case report. J Neurosurg. 1993;79(4):600-2.

10. Kantrowitz AB, Spallone A, Taylor W, Chi TL, Strack M, Feghali JG. Erythropoietin-augmented isovolemic hemodilution in skullbase surgery. Case report. J Neurosurg. 1994;80(4):740-4.

11. Colomina MJ, Bago J, Pellise F, Godet C, Villanueva C. Preoperative erythropoietin in spine surgery. Eur Spine J. 2004;13 Suppl 1(1): S40-9.

12. Forgie MA, Wells PS, Laupacis A, Fergusson D. Preoperative autologous donation decreases allogeneic transfusion but increases exposure to all red blood cell transfusion: results of a meta-analysis. International Study of Perioperative Transfusion (ISPOT) Investigators. Arch Intern Med. 1998;158(6):610-16.

13. Henry DA, Carless PA, Moxey AJ, et al. Pre-operative autologous donation for minimising perioperative allogeneic blood transfusion. Cochrane Database Syst Rev. 2002;2(2):CD003602.
14. Harlaar JJ, Gosselink MP, Hop WC, Lange JF, Busch OR, Jeekel H. Blood transfusions and prognosis in colorectal cancer: long-term results of a randomized controlled trial. Ann Surg. 2012; 256(5):681-6; discussion 686-7.

15. Glaspy J, Crawford J, Vansteenkiste J, et al. Erythropoiesis-stimulating agents in oncology: a study-level meta-analysis of survival and other safety outcomes. Br J Cancer. 2010;102(2):301-15.

16. Ludwig H, Crawford J, Osterborg A, et al. Pooled analysis of individual patient-level data from all randomized, double-blind, placebo-controlled trials of darbepoetin alfa in the treatment of patients with chemotherapy-induced anemia. J Clin Oncol. 2009;27(17):2838-47.

17. Singbartl G. Adverse events of erythropoietin in long-term and in acute/ short-term treatment. Clin Investig. 1994;72(6 Suppl):S36-43.

18. Stowell CP, Jones SC, Enny C, Langholff W, Leitz G. An open-label, randomized, parallel-group study of perioperative epoetin alfa versus standard of care for blood conservation in major elective spinal surgery: safety analysis. Spine (Phila Pa 1976). 2009;34(23):2479-85.

19. Hutton B, Fergusson D, Tinmouth A, McIntyre L, Kmetic A, Hebert PC. Transfusion rates vary significantly amongst Canadian medical centres. Can J Anaesth. 2005;52(6):581-90.

20. Bennett-Guerrero E, Zhao Y, O'Brien SM, et al. Variation in use of blood transfusion in coronary artery bypass graft surgery. JAMA. 2010;304(14):1568-75.

21. Goodnough LT, Saha P, Hirschler NV, Yomtovian R. Autologous blood donation in nonorthopaedic surgical procedures as a blood conservation strategy. Vox Sang. 1992;63(2):96-101.

22. Linsler S, Ketter R, Eichler H, Schwerdtfeger K, Steudel WI, Oertel J. Red blood cell transfusion in neurosurgery. Acta Neurochir (Wien). 2012;154(7):1303-8.

23. Devon KM, McLeod RS. Pre and peri-operative erythropoietin for reducing allogeneic blood transfusions in colorectal cancer surgery. Cochrane Database Syst Rev. 2009;21(1):CD007148.

24. Popovsky MA, Whitaker B, Arnold NL. Severe outcomes of allogeneic and autologous blood donation: frequency and characterization. Transfusion. 1995;35(9):734-7.

25. Canadia Blood Services. Report to Canadians 2011/2012. Available from: http://video.bloodservices.ca/Annual2012/index.html.

26. Shander A, Hofmann A, Ozawa S, Theusinger OM, Gombotz H, Spahn DR. Activity-based costs of blood transfusions in surgical patients at four hospitals. Transfusion. 2010;50(4):753-65. 